\title{
Dates Palm Farming Systems Sustainability and Risk Efficiency in Oman
}

\author{
Kheiry Hassan M. Ishag ${ }^{1}$ \\ ${ }^{1}$ Dhofar Cattle Feed Company, P.O. Box 1220, PC 211, Sultanate of Oman \\ Correspondence: Kheiry Hassan M. Ishag, Dhofar Cattle Feed Company, P.O. Box 1220, PC 211, Sultanate of \\ Oman. Tel: 96-899-490-564. E-mail: kheiryishag@ hotmail.com
}

$\begin{aligned} & \text { Received: September 16, } 2016 \quad \text { Accepted: October 4, } 2016 \quad \text { Online Published: October 27, } 2016 \\ & \text { doi:10.5539/sar.v6n1p39 }\end{aligned}$ URL: http://dx.doi.org/10.5539/sar.v6n1p39

\begin{abstract}
Date Palm is the most important cultivar in Oman and occupies 35\% of total cultivated area and $78 \%$ of the total fruit trees area. The Ministry of Agriculture and Fisheries attempted to improve Date production but due to climate change and environmental constrains agricultural production has shown instability in production and generated a desire to build a sustainable farming systems. The study used stochastic model to analyze Date Palm Farming Systems in Oman and identify the most sustainable and risk efficient one. Stochastic Efficiency with Respect to Function (SERF) technique use certainty equivalent concept to rank a set of risk efficient alternatives. The study found Batinah Region is the most risk efficient region and got a positive NPV with a probability of $88 \%$ followed by Dakhiliyah Region 77\% and Dahirah Region 67\%. The study also indicates Batinah and Dakhiliyah Regions which cultivate 52\% of total Date Palm area in Oman is located in risk efficient farming system areas. Risk premium analysis performed and shows Dakhiliyah Region farmers can pay up to RO 59 for replanting Date Palm tree and move to Batinah Region farming practices with less risky farming system. The farmer in Dahirah Region is willing to pay RO 144 per Date Palm tree to shift to more efficient farming system practices such as Batinah Region. Date Palm Farming System analysis should be used as a basis and foundation for replanting program and resources and environmental constrains need be considered. A right economic incentives to be given to encourage production of selected Date Palm varieties for each region to increase ecosystem resilience and economic benefit.
\end{abstract}

Keywords: Date Palm, simulation model, stochastic efficiency with respect to a function (SERF), risk efficient, resilience ecosystem, sustainability, farming systems

\section{Introduction}

The Date Palm cultivation is considered as the most important agricultural activities in Oman with a large number of varieties and spread over a large integrated ecological and farming system. It occupies $35 \%$ of total cultivated area and 78\% of the total fruit trees in Oman as per Ministry of Agriculture Statistics (2013).The Date Palm trees occupies about 57,430 acres and includes 6,79 Million productive trees. The total date production at year 2013 reached 308 thousand ton 53\% for direct human consumption, 20\% used as animal feed, 16\% for industry use and $11 \%$ for export.

Oman has about 200 date palm varieties and 30 types of these varieties are recognized as good varieties and have commercial and high market absorption demand. Top good varieties such as Khalas produce about $8 \%$ of total production and second top varieties date such as Zabad, Khanizi , Barni and Madlozi are commercial dates varieties and can be stored and sale off the season with a reasonable price. Oman benefited from different environmental and climate zones and adopted farming systems which extend the harvesting season to six months from May to November, (Kheiry Hassan M. Ishag et al., 1994). Accordingly date palm varieties can also be grouped as early, intermediate and late mature varieties. The early mature date palm varieties such as Nagal which is $11 \%$ from total dates production in Oman is cultivated at Batinah i.e. $38 \%$ and Dakhiliyah regions i.e. $30 \%$ of total Nagal production. Farad, Khanizi and Khalas are intermediate mature varieties and cultivated at Batinah and Sherqiah regions. A late mature Date variety such as Khasab is cultivated at Batinah and Dakhiliyah regions. However, farmers are diversifying date palm cultivated varieties to manage risk associated with price and yield uncertainty in term of extending harvesting period and producing different type of dates for different use i.e. human, industrial, animal feed. Farmers should manage to develop resilience agricultural systems by 
introducing affordable technologies and strategies such that ecosystem functions and services can be maintained and livelihoods can be protected, (Brenda B. Lin, 2011).

The date Palm farming systems in Oman can be grouped to six farming systems. Batinah Region considers as the leading region and produces 136 thousand tons in year 2013, which represent about $44 \%$ of the total date's production in Oman. The second region is Dakhiliyah Region and produces 63 thousand tons i.e. $20 \%$ followed by Sherqiah Region $14 \%$ and Dahirah Region which produce $11 \%$ of the total Oman production of Dates. Dakhiliyah Region got the highest Date Palm average productivity per tree with $62 \mathrm{~kg} /$ tree followed by Dahirah Region $47 \mathrm{Kg} /$ tree and Batinah $46 \mathrm{Kg} /$ tree and Sherqiah Region $39 \mathrm{Kg} /$ tree, and Muscat Region $30 \mathrm{Kg} / \mathrm{tree}$. Region production and Date Palm tree productivity depend on many factors such as date palm varieties, cropping pattern, soils and soil fertilities, irrigation system, water quality and availability and farming system resilience and survivals.

Social sustainability in term of consumers' preference of Dates products, short supply chain systems and availability of local Dates marketplace are required. In addition to Farm waste management, multifunctional farm's activities such as selling manure and feed dates to animal have important role in farming system sustainability, (Anna Gaviglio et al., 2016).

However, comparing Date Palm Regions in term of region production, number of date palm trees at each region and tree productivity ignoring farming systems profitability and economic sustainability will not give a full picture to understand problems and develop strategy for Date Palm sector in Oman, (Kheiry Hassan M. Ishag et al., 1997). As a result, farming system economic sustainability and risk efficiency is the most important issue need to be studied to provide data for policy advisers.

\section{Problem statement}

Date Palm is the most important cultivar in Oman and occupies 35\% of total cultivated area and $78 \%$ of the total fruit trees area. The Government Authority attempted to improve Date production through supporting Research, Extension and Farmers. The production increased during 1999-2001 and reduced due to environmental constrain, water resource shortages and drought climate in 2002 and 2004. The Ministry of Water Resources indicted that the annual ground water recharge quantity in Oman reaches (1295) millions $\mathrm{M}^{3}$ which is less than the total country water consumption of about $25 \%$. However, this unbalance water supply and demand is the main resources constrain facing Date Palm development program.

The Ministry of Water Resources stated that aquifers are recharged by rainfall and surface water of a bout (70\%) of water demand. The renewable water recharge shows that Batinah Region comes first in aquifer annual recharge, followed by Al Dakhliya and Al Sharqiya Regions. Due to water shortage and environmental constrains the Date Palm cultivated areas reduce recently by 36\% from 93,534 acres in year 2000 to 59,602 acres in 2013. The unsustainable date production situation encourages Government to announce for long term Date Palm development program and to cultivate One Million good varieties Date Palm trees. The study investigates and aims to identify the right land and sustainable farming system region that can accommodate this project and improve resilience systems.

\section{Literature review}

Farming system sustainability concern about system capability to maintain production in spite of major constrains and disturbance. The system resilience and ability to continue in the future in term of financial viability and farm resources degradation can be taken as a measurement to choice between alternative Date Palm farming systems, (Lien G. et.al., 2007). Stochastic and dynamic nature of the farming systems can be model and probability of getting positive return for each farming system can be calculated.

Monte Carlo Simulation Model used for project appraisal by (Savvakis C. Savvides, 1994). He outline that dynamic integrated analysis provided a range of outcomes that can decrease risk of uncertainty variables and give more reliable results to investor. Additional information regarding water management policy analysis and aquatic ecosystems can be found in (Folkes et al., 2002) ; (MA, 2005; Sanders and Lewis, 2003) ; (Blumenfeld et al., 2009; Carpenter, Brock and Hanson, 1999; Chen et al., 2009).

In this study we used Monte Carlo Simulation Models to quantify risk and uncertainty associated with Date Palm farming system. The quantitative risk analysis will estimate the probability of getting positive NPV for reach Region and provide decision makers a tool to improve Date Palm cultivation and achieving One Million Date Trees Project aims simultaneously: sustaining irrigated agriculture farming to achieve food security and maintain resources associated natural environment. (S. Quiroga, 2010) used Monte Carlo Simulations technique to estimate crop yield risk at different water resources variability. 
The stochastic efficiency of alternative Date Palm farming system can rank risky alternative over a range of risk aversion. The stochastic efficiency with respect to a function (SERF) technique developed recently by (Hardaker et al., 2004) and based on ranking risky alternatives in terms of expected utility function and certainty equivalents (CE). Certainty Equivalents is defined as the sure sum of the money with the same utility can be accepted to compensate risk alternative (Hardaker et al., 2004). The Stochastic Efficiency with Respect to a Function (SERF) used by (Lien et al., 2006) to assess organic and conventional cropping systems sustainability. (Eihab M. F. et al., 2011), used (SERF) methodology to analyze conventional and conservation tillage system from experimental plots data at Iowa State University. He argued (SERF) method is useful tool to assist policy makers and advisers on solving problems involving agricultural risk. In this study, the (SERF) technique is applied to assess a set of alternative risky farming systems. The SERF method ranked regional farming systems in terms of the CE over a range of risk aversion levels. SERF can compare any level of decision makers ${ }^{\text {ee }}$ preferences including different level of risk. The aggregated Date Palm area and production data at Regional level were calculated. These values were multiplied by average date price for each date varieties cultivated at each region. The stochastic simulation models were employed to examine NPV distribution for the six different Regions and their Date Palm farming system alternatives. The research aimed to investigate Date production regions and their Date Palm farming system sustainability and risk efficiency over a range of risk aversion level.

\section{Methodology}

The farming system evaluation and viability is depending on estimating the future values of the crops return and operation costs by using available information from a specific situation in the past. The normal approach used in investment appraisal is to calculate a "best estimate" of the variables based on the available data and use it as an input in farming appraisal model. The regional (NPV) is calculated as the most likely outcome of the farming system.

\subsection{Net Present Value}

The NPV of regional farming system was used to evaluate economic sustainability. The net cash flow for reach region is calculated by subtracting the cost from the revenue and discounted by the interest rate to obtain the NPV of the Region. The variables identified in term of deterministic and stochastic variables and NPV obtained as a range of values instead of a single value in a conventional financial evaluation.

\subsection{Monte Carlo Simulation}

Monte Carlo Simulation Model is a computerized algorithm model designed to evaluate the variability of the input variables of a model. The model can be used to estimate the effects of main variables on project outputs. The process started with the identification and assessment of the key variables. Then the probability density function is estimated to fit the best range of uncertainty around the expected value. The historical Date Palm data at each region obtained from MAF statistics (2013) and Date Palm Production Survey (2013). The Monte Carlo Simulation model including these variables is then run using random generated input values taken from the probabilistic distribution function. The model combines inputs and generate the estimated outcome value for (NPV). Monte Carlo Simulation Model is currently recorded as the most powerful technique can be used to incorporate risk and uncertainty. The model is suitable for complex project and the more risky and uncertainty variables associated within the project.

Monte Carlo dy-namic simulation model is used in this research for the evaluation of farming system economic sustainability and risk efficiency within different level of risk aversion. The stochastic budgeting methods are used to incorporate risk and uncertainty variables in Date Palm farming system in Oman. The study used @ Risk 7.5 program from (Palisade Corporation, Ithaca, New York) and add-in for Excel was utilized to account for stochastic nature of key farming system variables in the model. Parameters in Table 1 and input distribution were obtain from historical data and used in the model to estimate cash flow for each region.

\subsection{Stochastic Efficiency with Respect to a Function (SERF)}

SIMETAR program (2011) was used to carry on SERF analysis to assess Date Palm farming systems risk efficiency and sustainability under different level of risk aversion. The whole region stochastic simulation model was used and model is run for 10 years in the future to calculate NPV for each region and assess the economic sustainability of different farming system alternatives. The negative NPV indicates project failure and less risk efficient alternative (Hansen and Jones, 1996).

The Certainty Equivalent graphs were also constructed to display and rank Date Palm farming systems according to risk efficiency across the specified range of ARAC values and farming system with higher CE is preferred to those with lower CE. The risk premiums were also calculated for each region by subtracting less preferred 
alternative regional $\mathrm{CE}$ values from preferred $\mathrm{CE}$ values at given ARAC values. Given a utility function $\mathrm{u}(\cdot)$, a random wealth variable $\mathrm{X}$, and an initial level of wealth $\mathrm{w} 0$, the certainty equivalent is :

$$
\mathrm{CE}=\mathrm{u}-1\{\mathrm{E}[\mathrm{u}(\mathrm{X}+\mathrm{w} 0)]\}-\mathrm{w} 0,
$$

The risk premium measure the minimum amount that would have to be paid to a farmers and decision maker to justify a switch from alternative present farming system to other less risky Date Palm farming system. An analysis of Date Palm farming system of six regions was conducted using a ten year farm level data and simulation model. Total number of Date Palm trees and varieties for each region, yield, price, investment and operation cost are collected from Date Palm Production Survey and Ministry of Agriculture Statistics (2013). The model simulates the costs and returns of the farm for six regions and the NPV probability distributions generated by the simulation model and used to rank the best alternative region across a full range of RACs.

\subsection{Data Collection}

Historical data were collected to perform partial budgeting analysis for six alternatives Date Palm farming systems in Oman and consider parameters such as date palm trees varieties, number of date palm panted trees, regional date yield, sale price, cost of inputs and other operation cost for each region. The study used simulation analysis to identified main stochastic variables need to be incorporated in the model such as Date Palm trees varieties cultivated for each region, Date yields, inputs cost, and sale prices for each. The probability distributions of the risky input variables (triangle - normal - bionomial) identified and Cumulative Distribution Function (CDF) of the output (NPV) for each region were calculated.

The Date Palm farming system sustainability was investigated by performing Stochastic Efficiency with Respect to a Function (SERF) Analysis for six regions. SIMETAR (2011) program was used to calculate and generate Certainty Equivalent (CEs) for each region and rank alternatives regions as per their risk efficiency. The data used in this study obtained from different sources such as Ministry of Agriculture statistics (2013), Date Palm Production survey (2013) and previous studies and can be grouped in to two categories as under :

Regional level data for Date Palm farming systems in six regions :

- Regional data and current farming systems data such as intercropping and cropping pattern.

- Regional level data such as Date Palm varieties (yields, price, operation costs) for each region.

- Irrigation system, water quantity available for each region, water and soil salinity.

- Regional Date Palm varieties use (human use, industrial use, animal feed) and consumptions.

- Regional Dates marketing, harvesting time and duration and market price.

- Regional level historical data for Date Palm Farms area development at different region.

Farm level data and capital cost of cultivation one Acre :

- Cost of land preparation and Date offshoots planting trees.

- Operation cost for each Date Palm varieties at each region.

\subsection{Model Structure}

The study started modeling process by defining inputs and parameters effecting Date Palm cultivation income and return. The qualitative risk analysis in this study is aim to provide a high level of understanding of risks facing farming system sustain Date Palm growing in Oman. Such analysis may increase attention of old Date Palm trees replacement policy adviser to the top risks they need to manage effectively, (Qiu Ling Guo, 2001) and (James, 2007).

Percentage of annual yield increase, sale price and cost increase and total Date production for each region are collected and calculated from regional historical data. The market absorption Date varieties rate for each region is calculated from Date Palm production and marketing survey historical data.

The main risk and uncertainty variables identified in the models were:

- Low market absorption Date varieties.

- Cost of establishing Date farm and capital cost increase for each region.

- Total Date Palm trees and varieties grown at each region.

- Dates products selling price volatility for each varieties grown at each region.

- Cost of production per ton for each region. 
- Annual increase in sales price and unit cost.

- Total Date saleable volume for each variety at each region.

- Date Palm trees yield variation at six regions.

The region financial performance and cash flows is performed after selecting key parameters and the probability of all individuals risk combined on parameters. The model run and result of the analysis generate the probability that region will meet its quantitative objectives and cash flow projection. The probability distributions of the parameters are incorporated in to simulation model to quantified risks range for each region, Table 1 . Six models formed and constructed to represent six regions and their Date Palm farming system. The models run with @ Risk add-in software to test economic viability and sustainability for each region and farming system.

Table 1. The main input parameters distribution used in Batinah Region Faming System Model

\begin{tabular}{lllllll}
\hline Risk & Affects & Distribution & Absolut/ percentage & \multicolumn{3}{c}{ Impacts } \\
\cline { 5 - 7 } & & & & Min & Most likely & Max \\
\hline 1st year yield & Revenue & Normal & Absolut & 60000 & 78203 \\
Low market absorption var. & Revenue & Normal & Percentage & $23 \%$ & \\
Increase in yield ton & Revenue & Triangular & Percentage & $2 \%$ & $2.5 \%$ & $3 \%$ \\
Sale Price/ton & Revenue & Triangular & Absolut & 450 & 650 & 850 \\
1st year unit cost/ton & Cost & Triangular & Percentage & $29 \%$ & $35 \%$ & $60 \%$ \\
Increase in sales price & Revenue & Triangular & Percentage & $1 \%$ & $2 \%$ & $3 \%$ \\
Increase in cost & Cost & Triangular & Percentage & $1 \%$ & $2 \%$ & $3 \%$ \\
\hline
\end{tabular}

Latin hypercube sampling technique and procedure used calculate NPVs for each region and statistic results generated after 5000 number of iterations runs. In the simulation, values of parameters entering into the model were chosen from their respective probability distributions by Latin hypercube sampling technics and were combined according to functional relationships in the model to determine whole region outcome and return i.e. NPV.

The Cumulative Distribution Functions (CDFs) of NPVs for each region is generated by repeating the process for a large number of times to give estimates of the output distributions of farming system performance and economic viability. SIMETAR program was used to calculate Stochastic Efficiency with Respect to a Function (SERF) and evaluate farming system risk efficiency and rank farming system regions within different level of risk preferences. The study finally performed $\mathrm{CE}$ analysis to estimate risk premium price and subsidy should be given to farmers to replant Date Palm trees in a less risky farming system practices and utilizing their poor farm land, saline soil and poor water quality in a sustainable manner.

\subsection{Farming System Risk Allocation}

The risks of Date Palm farming systems are normally shared by farmers within the region in term of irrigation system, water availability, water and soil salinity and Date Palm pests and diseases. However, some farmers are better able to cope with certain specific risks than others and grow water salinity and drought tolerance varieties. Resilience of farming system could be achieved by Date Palm diversification and risk-sharing. A reasonable risk-taking offset and optimizing risk allocation within the farmer in the same region can help farmers to cope with un-control risk facing some region and mitigate water pumping restriction in some areas.

The main risks cannot be control by Date Palm farmers:

- Risk of yield reduction: The risk of low yield that could not cover operation and investment cost.

- Risk of Dates sale price reduction: The sale price during the season is low and farmers need to sell their products to recover operation cost and loans repayment.

- High price vulnerability and total volumes of un-marketable Dates for each region (markets absorb rate).

- $\quad$ Risk of increasing operation cost: Increase of raw material, operation and maintenance cost.

- Risk of increasing capital cost: Risk of Dates trees replanting cost increase due to offshoots price increase.

Date Palm farming system risk efficiency and economic sustainability could be increased and enhanced by farmers' attitude and perception of risk sharing strategies. 


\section{Result and Discussion}

\subsection{Date Palm Farming Systems in Oman}

Oman is located within Date Palm Belt area $\left(15-27^{\circ}\right)$ north latitude with long summer season extended for six months and warm winter and low rain fall. Date Palm farming system in Oman can be grouped into two main farming systems spread over six regions. The country date production in year 2013 reached 308427 tons, $44 \%$ from Batinah Region, 21\% Dakhiliyah Region, 15\% Sherqiah Region, 11\% Dahirah Region, 3\% Muscat Region, $2 \%$ Musandam Region and 4\% from others area. Farming system for each region can be descripted as under.

\subsubsection{Coastal Farming System}

The Coastal Farming System is coastal oasis farming system type located near the sea in low lying land and regular floods from mountains allowed considerable aquifer recharge and leaching salt from soils. The land located far distance from sea has sweeter and deeper irrigation water and crop is irrigated with wells, Tariq M. Alzidgali et al. (1993). The Coastal Farming System includes 57\% of total Date Palm trees and produce 54\% of Oman production. However, this farming system can be represented by Batinah Region, Muscat Region and Musandam Region.

\subsubsection{Batinah Region}

Batinah Region is a top region in Date Palm area, production and number of cultivated Date Palm trees i.e. 2.5 Million trees. Batinah Region can be grouped to three different farming systems zone:

Coastal area: The area is located in a tropical climate zone and characterized by high temperatures and humidity with high saline water and soil and low yield date palm trees. Date Palm is cultivated in intercropping with Alfalfa and lime trees and small area of vegetables and cereal crops is grown. The rapid expansion of cultivated area created water deficit in aquifer recharge and compensated by sea saline water and vegetable and Alfalfa crops moved inland. Date Palm cultivated varieties dominated by low yield, water and soil tolerance and stable varieties such as Um-Silla and Mabsali. Fishing activities is practices and dried dates are exported.

Sahel area: The area is located next to coastal area with a medium farm size (5-15 acres) and well-organized farms and use modern irrigation systems. Irrigation water is less saline and water quality determined the cropping pattern in this area. The climate is dry and Rhodes Grass crop is dominant cultivated crop. Farmers use fertilizers and pesticide and chemicals and modern bumps for irrigation. Date Palm cultivated varieties dominated by good quality and high yield varieties such as Khalas and Khasab and low yield variety such as Um-Silla which is used for human and animal feed.

Large Modern Farms area: The area is located next to Sahel area near mounting area and established recently as a large commercial farm. Date Palm cultivated with Rhodes Grass crop and Alfalfa and fruit trees. Date Palm cultivated in this area is of good quality varieties and cropping density is low compared to other regions.

Batinah Region cropping pattern dominated by fruit trees i.e. $60 \%$ such as dates, mango and lime trees, $20 \%$ forage crops and $20 \%$ vegetable crops. All agricultural operations are cared out by unskilled expatriates labour. Batihah Region has three Date cultivation zones and grows 31 Date Palm sustainable varieties. Date Palm area decreased from 28560 acres in year 2000 to 20278 acres in 2013 to maintains resilience farming system through resources management and crop diversification and recorded as resilience and sustainable Region in Oman.

\subsubsection{Muscat Region}

Muscat Region is the fifth region in term of production area and number of trees i.e. 289303 Date Palm trees. Farms in Muscat region are small and Date Palm area start declining due to urbanization and farm land reclassification. The average Date Palm tree production in year 2013 recoded as $31 \mathrm{Kg} /$ tree, Table 2 .

\subsubsection{Musandam Region}

Musandam Region is dominated with mounting area and low production varieties are grown with an average of $30 \mathrm{Kg} / \mathrm{trees}$. The total Date Palm cultivated area in year 2013 is 1497 acres and produce 6503 ton of dates.

\subsubsection{Interior Farming System}

The Interior Farming System located inland and experience with small farm areas and date grown in intercropping systems and high density plantation is recorded. The farming system has a dry climate area with low humidity. Farms irrigate crops with Al Falaj irrigation system and with good water quality. The Interior Farming System includes 43\% of total Date Palm trees and produce 46\% of Oman production. However, this farming system can be represented by Dakhiliyah Region, Dahirah Region and Sherqiah Region. 


\subsubsection{Dakhiliyah Region}

The Dakhiliyah Region is the third top region in term of cultivated number of Date Palm trees i.e. 905 thousand trees and fourth in area and second in production. Water resources in this region are limited and farmers have a good experience of date palm cultivation and high yield Date Palm varieties such as Khalas, Fardh and Nighal are cultivated with the highest yield per tree i.e. $62.5 \mathrm{Kg} / \mathrm{tree}$.

\subsubsection{Dahirah Region}

Dahirah Region farming system is the third Region in term of Date Palm cultivated area (6134 acres) and fourth in term of production and number of Date Palm trees i.e. 670 thousand trees with average production of 47 $\mathrm{Kg} / \mathrm{tree}$. Farahd and Khalas Date Palm varieties are cultivated at this region, table 2.

\subsubsection{Sherqiah Region}

Sherqiah Region is the second top region in Date Palm area and number of Date Palm trees i.e. 1.04 Million trees and recorded as the third region in production in year 2013. Date Palm trees are grown in Oasis agro-ecosystem area with loamy and sandy soil. The Date Palm is grown in intercropping and irrigated with Al Falaj Irrigation system and good quality of dates are grown such as Khalas, Hilali and Khasab varieties and Mabsaly for export.

Table 2 shows that in Dakhiliyah and Batinah regions farmers are grown more date palm varieties to extend harvesting time and mitigate risk and cope with yield uncertainty and price volatility. The total number of Date Palm varieties grown in Dakhiliyah and Batinah regions is 22 and 31 respectively. The Research Center in Oman recommends plant density of 65 date palm trees per Acre as the correct and appropriate planting density. Table 2 shows Date Palm planting density in Dakhiliyah and Batinah regions are low compare to other regions, and this may explain the reasons for high yield and production of date per acre in these regions and adaptation with climate changes. Crop diversification and inter cropping practices is also observed at Dakhiliyah Region and improve ecosystems.

Table 2. Date Palm Number of varieties, tree density and production for each Region in Oman (2013)

\begin{tabular}{lllllll}
\hline Location & Muscat & Musandam & Dakhiliyah & Batinah & Sherqiah & Dahirah \\
\hline Date Varieties & 17 & 13 & 22 & 31 & 19 & 13 \\
Density/acre & 91 & 143 & 34 & 53 & 90 & 121 \\
Production kg/tree & 31.18 & 30.39 & 62.53 & 46.41 & 39.09 & 46.98 \\
Production ton/acre & 2.99 & 4.34 & 6.67 & 6.71 & 3.87 & 5.69 \\
Number of trees & 289303 & 191124 & 905126 & 2546071 & 1036361 & 670265 \\
Production ton & 10145 & 6503 & 63237 & 136132 & 44360 & 34947 \\
Establishment cost & 1456 & 2145 & 850 & 318 & 2070 & 2299 \\
Revenue & 1944 & 2821 & 3335 & 4362 & 2089 & 4268 \\
Operation cost/acre & 682 & 1382 & 1501 & 1527 & 1149 & 1920 \\
Net return & 1262 & 1439 & 1834 & 2835 & 940 & 2348 \\
\hline
\end{tabular}

\subsection{Monte Carlo Simulation Models Run Results}

The study investigated the regional economic performance and sustainability and calculates NPV by using regional data level. Batinah Region recoded the highest NPV i.e. 158 million Rials followed by Dakhiliyah 104 million and Dahirah 61 million as shown in Table 3. However, this indicates that net present value calculation is useful for investigating economic performance measurements, but it is also important to obtain the variation between NPVs and calculate the CVs and SDs as a risk measurement tools and decision support factors.

The Coefficient of Variation of the probability distribution of NPV was low for Batinah and Dakhiliyah regions and indicates regional farming system sustainability and risk efficiency. The smaller CVs and variance between NPVs i.e. (Batinah \& Dakhiliyah) makes CDF curve steeper and less risky, whereas larger variance and CVs makes CDF curve flatter Figure 2. The result also shows that Batinah Region will get a positive NPV with 88\% probability and Dakhiliyah Region get positives NPV with 75\% probability, Table 3. Musandam and Dahirah Region model show a low Skewness figure which indicates downside risk control farming systems. 
Table 3. Date Palm Farming System in Oman-Statistics for NPVs (000) for each Region

\begin{tabular}{|c|c|c|c|c|c|c|}
\hline Models & Model (1) & Model (2) & Model (3) & Model (4) & Model (5) & Model (6) \\
\hline Location & Muscat & Musandam & Dakhiliyah & Batinah & Sherqiah & Dahirah \\
\hline Mean (000) & 5127 & 5396 & 104474 & 157960 & 53048 & 61189 \\
\hline SD (000) & 38174 & 144834 & 157040 & 146286 & 135335 & 158766 \\
\hline $\mathrm{CV}$ & $744 \%$ & $2684 \%$ & $150 \%$ & $93 \%$ & $255 \%$ & $259 \%$ \\
\hline Skewness & -0.048 & 0.007 & 0.226 & 0.509 & 0.433 & -0.071 \\
\hline Kurtosis & -0.107 & 0.081 & 0.501 & 0.816 & 1.029 & 0.357 \\
\hline $\operatorname{Min}(000)$ & (103 033) & (467 998) & (366 014) & (250 903) & $\left(\begin{array}{l}381 \\
082\end{array}\right)$ & (583 940) \\
\hline Max & 134357 & 417779 & 735539 & 751035 & 609637 & 539521 \\
\hline Range & 237390 & 885777 & 1101553 & 1001938 & 990719 & 1123461 \\
\hline
\end{tabular}

The cultivated Date Palm varieties have an important and major effect on NPV for each region. The early and late maturity dates has a high market absorption demand and can be sold with high price off season. Moreover, dates for human consumption such as (Khalas, Khasab, Hilali) has high market absorption rate and can be sold with high price within the season, whereas dates used for industrial purposes such as (Farad, Mabsili) and for animal feed such as (Um-Silla) has a low market price.

The Batinah Region produces $93 \%$ of total Um-Silla country production. This variety is sustainable and water salinity tolerance variety, as a result, region production from this variety increased from 25885 tons in 1997 to 28791 tons in 2013 due to resilience and propensity of region farming system and its ability to retain productivity and cope with water deficits and water salinity risk increase. However, this variety contributes about $24 \%$ of region date production and is a late maturity date variety and can be stored and consumed as dry date off the season. The second varieties in Batinah region is Shahl i.e. $13 \%$ followed by early maturity variety Naghal i.e. $11 \%$ and consumer favorites and premium price late maturity variety Khasab i.e. $10 \%$ of date production.

The cropping pattern analysis is performed for all regions and shows that fruit crops (including Dates) occupied $54 \%$ of the total cultivated area followed by forage crops $27 \%$, vegetables $12 \%$ and field crops $6 \%$, Figure 1 . Date Palm area for the country has been reduced from 93,534 acres in 2000 to 59,602 acres in 2013 to cope with water shortage problems. Batinah Region reduced fruits trees, field crops, forage areas and Date Palm area by $29 \%$ from year 2000 to year 2013. Dakhiliyah and Sherqiah Regions use intercropping system and increased forage crops and fruit trees areas by cultivating Alfalfa under fruit and Date Palm trees. Farmers get multiple benefits and obtain additional income from forage, Dates, fruits and vegetables, and improve soil fertility from leguminous forage and enhancing water productivity (yield per unit of water consumed) when irrigation is used for intercropped fields.

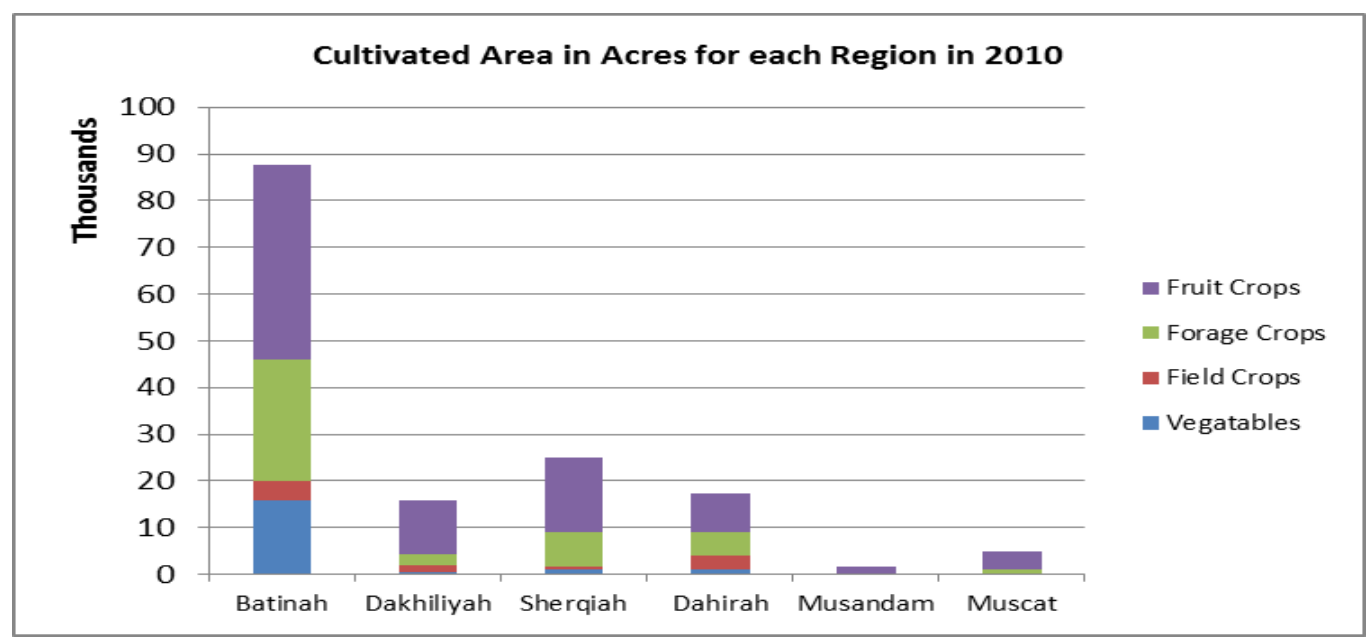

Figure 1. Cultivated Area in Acres and Cropping Pattern for each Region in Oman 2010.

\subsection{Date Palm Regions and Cumulated Distribution Function Analysis}

To test Date Palm Farming System sustainability the Cumulated Distribution Function CDF graphs performed to illustrate the range and probabilities of NPV for combinations of farming system for each region. Due to CDF 
lines cross in the graph we could not ranked regions and their Date Palm Farming System sustainability by using first degree stochastic dominance, and Stochastic Efficiency with respect to a Function (SERF) is performed to have a good ranking analysis and most risk efficient region and farming system alternatives. The analysis indicates Batinah Region farming system distribution line on the right is preferred to those on the left.

Muscat Region Date Palm farming system could not manage downside risk and were not viable and less efficient due to low profit and probability of getting positive return which is 54\% only. Figure 2 shows Batinah Region Farming System with a curve on the right side of the graph is a less risky and most sustainable farming system. The Dakhiliyah Region is the second most risk efficiency and got a probability of $75 \%$ to achieve a positive NPV. The study indicates Batinah and Dakhiliyah Regions which cultivate 52\% of total Date Palm area in Oman is located in risk efficient farming system areas.

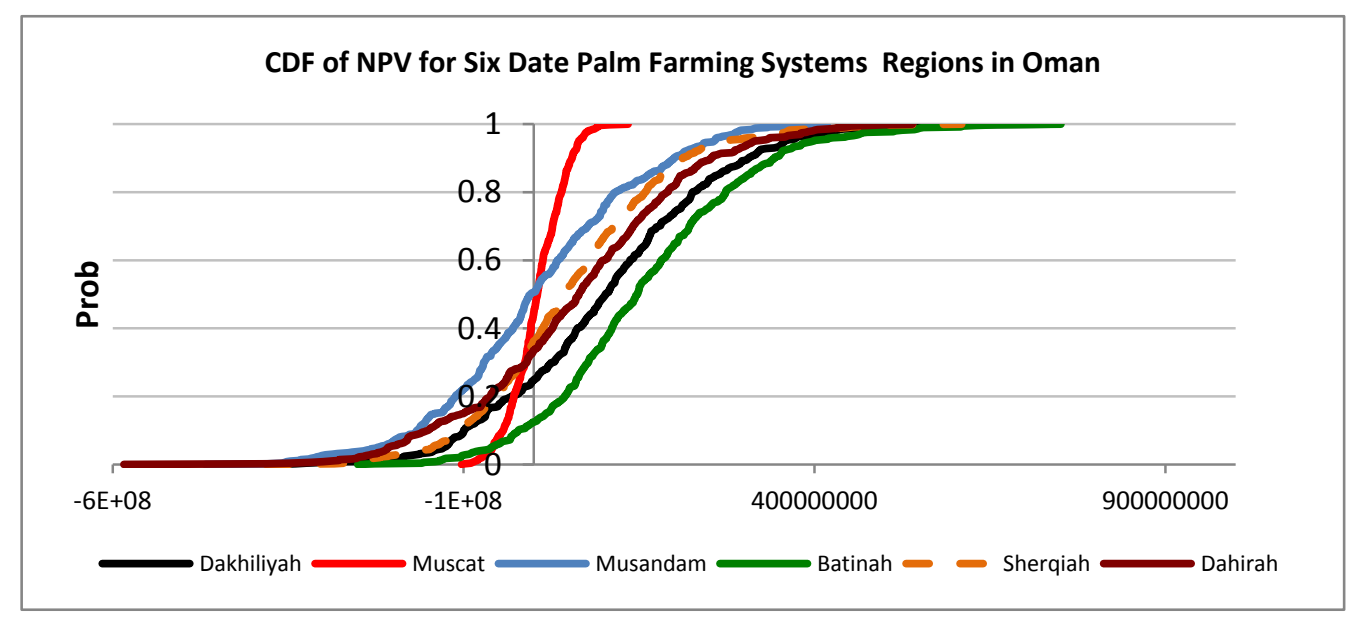

Figure 2. Comparison of 6 CDF of NPVs of Regions' Dates Palm Farming Systems in Oman.

\subsection{SERF Analysis and Farming System Certainly Equivalent}

The SERF analysis performed and calculated Certainly Equivalent values over a range of absolute risk aversion coefficients and represent different decision makers' degree of risk aversion. Decision makers are risk averse if ARAC below (0), risk neutral if ARAC equal (0) and risk preferring if ARAC more than (0) figures. The ARAC values used in this study represent risk neutral, rather risk and extremely risk averse as shown in Figure 3.

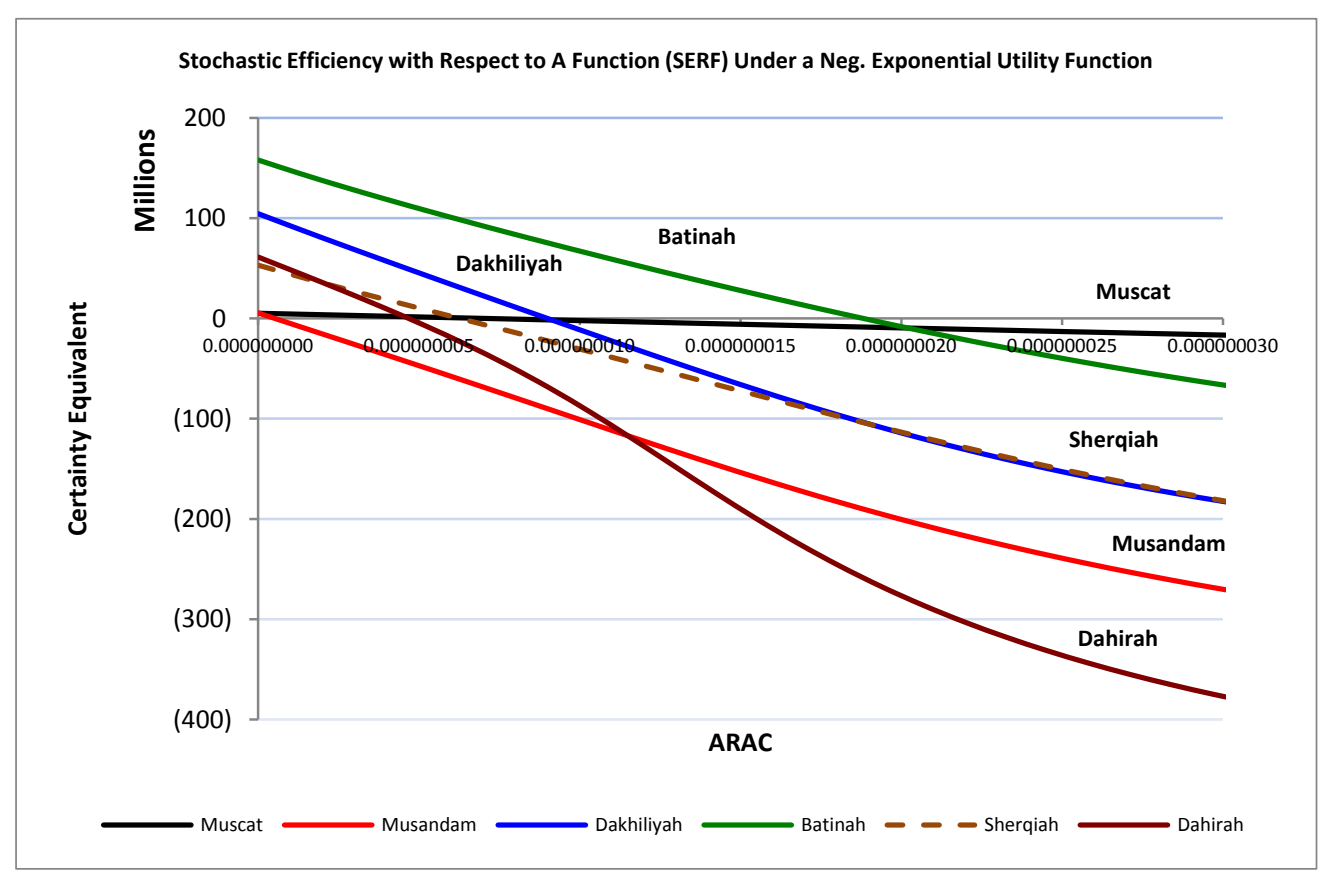

Figure 3. SERF for NPVs of six Date Palm farming system in Oman.

In Figure 3 above the SERF analysis is performed by using SIMETAR software program to compare six farming 
system alternatives simultaneously for all ARAC values in the range from $(0.000000)$ to $(0.000000018)$, and identified Batinah Region alternative as most risk efficient under all risk aversion. Under risk rather with (0.000000008) ARAC Batinah and Dakhiliyah Farming systems are risk efficient and Batinah farming system is the only efficient farming system under extremely risk aversion level. Muscat Region ranked as second most efficient farming system extremely risk aversion level as shown in Table 4.

Table 4. Ranking of Risky Alternatives by Risk aversion using CE for NPV $(000,000)$ of Regions

\begin{tabular}{lllllllll}
\hline Risk degree & Normal Risk & \multicolumn{3}{l}{ Rather Risk } & \multicolumn{2}{l}{ Rather Risk } & \multicolumn{3}{c}{ Extreme Risk } \\
\hline ARAC & 0.0000000 & & 0.000000005 & 0.000000008 & & 0.000000018 & \\
\hline Rank & Alternative & CE & Alternative & CE & Alternative & CE & Alternative & CE \\
\hline 1 & Batinah & 158 & Batinah & 108 & Batinah & 85.77 & Batinah & 5.15 \\
2 & Dakhiliyah & 104 & Dakhiliyah & 43 & Dakhiliyah & 14.05 & Muscat & -8.07 \\
3 & Dahirah & 61 & Sherqiah & 8.9 & Muscat & -0.529 & Dakhiliyah & -96.79 \\
4 & Sherqiah & 53 & Muscat & 1.4 & Sherqiah & -12.14 & Sherqiah & -97.95 \\
5 & Musandam & 5.4 & Dahirah & -6.88 & Dahirah & -46.56 & Musandam & -183.49 \\
6 & Muscat & 5.1 & Musandam & -48.9 & Musandam & -79.57 & Dahirah & -249.90 \\
\hline
\end{tabular}

The study ranks six alternative farming systems using SERF, over the range of risk normal, rather risk and extremely risk averse. The results are presented graphically in Figure 3 and numerically in Table 4. The study reveals that under normal risk aversion all Date Palm Farming Systems NPV are positive and Batinah, Dakhiliyah and Dahirah got the first, second and third ranking alternatively. Under rather risk (8.08E) only Batinah and Dakhiliyah got a positive CE values and under extreme risk only Batinah Region got a positive CE values. Table 4 also shows that Batinah Region is the most sustainable farming system in Oman and got a positive $\mathrm{CE}$ value even under extremely risk aversion.

\subsection{Risk premium and Date Palm replacement policy}

Risk premiums measure the value of the preferred alternative farming system over a less preferred alternative. The risk premium can be calculated by subtracting the CE value of less-preferred farming system alternative from CE value of the preferred one at each RAC level. The SERF analysis can help Decision Maker's with deferent risk preferences to select risk efficient farming system alternatives as per their risk aversion level.

Figure 3 show the difference between farming systems' CEs value which represents Decision Makers willingness to exchange the preferred (Date Palm Farming System) risky alternative for another less-preferred risky farming system alternative. The value of WTP is calculated as the difference between the CE for a risky farming system alternative and represents the date palm replacement payment and subsidy necessary to make the farmers and investors indifferent between the less-preferred farming system alternative and the preferred farming system alternative (Batinah Region):

$$
\text { WTP }=\text { CEpreferred }- \text { Cealternative }
$$

The SERF rankings methodology and WTP calculation are used to examine farming system sustainability and Date Palm replacement policy and strategies needed in Oman. Figure 3 shows that Batinah Region is most preferred farming systems under normal risk aversion, followed by Dakhiliyah, Sherqiah and Dahirah under normal risk aversion. From table 4, it is evident that Decision Makers for Date Palm replacement program should give more attention and support to risky regions i.e. Dahirah, Muscat and Musandam Regions. The study also indicates that Batinah Region benefit from date variety and crop diversification and increase ecosystem resilience and economic benefits. Dakhiliyah and Sherqiah Regions benefit from intercropping system and enhance water productivity.

\section{Conclusion}

The main objective of this paper is to identify Date Palm Farming System sustainability and ranked them over the range of risk aversion levels. The study also evaluate Date Palm cultivation viabilities in Oman and estimate economic sustainability through calculation of future values of different Date Palm Farming System and 
projected net cash flows by estimating yield and price and other main key variables which effect NPV and farming system sustainability. The whole region stochastic model using historical data of Date Palm cultivated area, number of trees, yield and price for each region is constructed. The risk and uncertainty associated with Date Palm farming systems and farming practices at different regions in Oman incorporated in the analysis. The stochastic character and shape were also incorporated by identifying probability distribution for each uncertain variable.

The study reverses that all Date Palm Farming System in Oman are viable and got a positive NPV at normal risk aversion level. The Batinah Date Palm Farming System recorded as the most risk efficient and economic sustainable system with $88 \%$ probability of achieving positive NPV, whereas Musandam farming system got a positive NPV with low probability of $49 \%$ only. Dakhiliyah farmer grows high yield and Date quality varieties such as Khalas, Khasab, Hilali for human consumption, whereas Sherqiah farmers grows Mabsili Date variety for export as dried boiled Dates. Farmers in these regions are manage to develop resilience agricultural systems by introducing tolerance Date Palm varieties and using affordable technologies and strategies such that ecosystem functions and services can be maintained and livelihoods can be protected. Although Batinah Region has a highest water deficit consist of $69 \%$ of total country deficit but the region mange to cope with the risk and ranked as the most risk efficient region in Oman by adjusting cropping pattern water requirement with annual underground water recharge and Region water supply.

Batinah and Dakhiliyah Regions farmers are diversifying date palm cultivated varieties to manage risk associated with price and yield loss uncertainty and extended harvesting period to six months to mitigate market access risk. Moreover, Batinah and Dakhiliyah managed to cope with water shortage and environment constrains by cultivating and producing different type of dates for different economic use i.e. direct human consumption, industrial, export and animal feed use. Batinah Region produces 93\% of Oman production from Um-Silla variety to cope with water salinity risk and compensate animal feed shortage.

The study indicates that local Date Palm verities cultivated in Oman are well adapted to environment and underground water limitation and other social economic attributes and constrains. The Date Palm Farming System shows its resilience, persistence and survivals under risk and uncertainty shocks in the future and Batinah Region ranked as the most risk efficient farming system under all risk aversion levels.

Risk premium analysis indicates that Dakhiliyah Region farmers can pay up to RO 59 for replanting Date Palm tree with a sustainable variety to avoid price and yield reduction risk he is facing and to move to Batinah Region farming practices with less risky farming system. The farmer in Dahirah Region is willing to pay RO 144 per Date Palm tree to shift to more efficient farming system such as Batinah Region farming system.

Date Palm Farming System analysis and finding of this study should be used as a basis and foundation for replanting program and selecting of Date Palm varieties, planted area, cropping pattern at each region. Crop and livestock activates interaction and resources and environmental constrains should be considered. Date Palm replacement program and policy makers should give economic incentives needed to encourage production of selected sustainable Date Palm varieties and crop diversification that suit and mitigate risk for each region.

\section{Acknowledgements}

The author thanks Mr. Al Hag Bakhit from Directorate General of Agriculture Dhofar Region-Ministry of Agriculture and Fisheries for providing Data and comments that greatly improved the manuscript.

\section{Competing interests}

The author declared that he has no competing interest and declared that the research was conducted in the absence of any commercial or financial relationships that could be construed as a potential conflict of interest.

\section{References}

Anna, G., Mattia, B., Maria, E. M., Eugenio, D., \& Alberto, Pirani. (2016). The social pillar of sustainability: a quantitative approach at the farm level. Agricultural and Food Economics, 4, 15. http://dx.doi.org/10.1186/s40100-016-0059-4.

Brenda, B. L. (2011). Resilience in Agriculture through Crop Diversification: Adaptive Management for Environmental Change. BioScience, 61(3), 183-193. http://dx.doi.org/10.1525/bio.2011.61.3.4

Blumenfeld, S. L., Christophersen, C. T., \&Coates, D. (2009), Water, Wetlands and Forests. A Review of Ecological, Economic and Policy Linkages. CBD Technical Series No. 47. Montreal/Gland, Switzerland, Secretariat of the Convention on Biological Diversity and Secretariat of the Ramsar Convention on Wetlands. 
Carpenter, S., Brock, W., \& Hanson, P. (1999). Ecological and social dynamics in simple models of ecosystem Management. Conservation Ecology, 3(2), 4. http://www.consecol.org/vol3/iss2/art4/

Chen, X. D., Lupi, F., He, G. M., \& Liu, J. G. (2009). Linking social norms to efficient conservation investment in payments for ecosystem services. Proceedings of the National Academy of Sciences of the United States of America (PNAS), 106, 11812-17. http://dx.doi.org/10.1073/pnas.0809980106

Eihab, M. Fathelrahman, J. C., Ascough, II, Dana, L. H., Robert, W., Malone, P. H., Lori, J. W., \& Ramesh, S. K. (2011). Economic and Stochastic Efficiency Comparison of Experimental Tillage Systems in Corn and Soybean Under Risk. Expl Agric, 47(1), 111-136. http://dx.doi.org/10.1017/S0014479710000979

Folke, C., Carpenter, S., Elmqvist, T., Gunderson L., Holling, C. S., \& Walker, B. (2002). Resilience and Sustainable Development: Building Adaptive Capacity in a World of Transformations. Scientific Background Paper on Resilience for the process of the World Summit on Sustainable Development on behalf of the Environmental Advisory Council to the Swedish Government. Interdisciplinary Center of Natural Resources and Environmental Research, Stockholm University, Sweden. http://dx.doi.org/10.1579/0044-7447-31.5.437

Hardaker, J. B., Richardson, J. W., Lien, G., \& Schumann, K. D. (2004). Stochastic efficiency analysis with risk aversion bounds: a simplified approach. Australian Journal of Agricultural and Resource Economics, 48, 253-270. http://dx.doi.org/10.1111/j.1467-8489.2004.00239.x

Hansen, J. W., \& Jones, J. W. (1996). A system framework for characterizing farm sustainability. Agriculture Systems, 51, 185-201. http://dx.doi.org/10.1016/0308-521X(95)00036-5

James, W. R., Brian, K. H., Joe, L. O., \& Chope, G. II. R. (2007). Including Risk in Economic Feasibility Analyses: The Case of Ethanol Production in Texas. Journal of Agribusiness, 25, 2.

Kheiry, H. M. I., \& Al-Marzogi, M. H. (1997). Date Palm Development Strategy in Oman. Directorate General of Agricultural Research, Ministry of Agriculture \& Fisheries, Sultanate of Oman, Muscat.

Kheiry, H. M. I., Al-Marzogi, M. H., \& Riad, S. A. D. (1994). Technical and economic constrains of date palm sector and farming systems in Sultanate of Oman, Report submitted to AFESD, IFAD and IDB. Syria.

Lien, G., Hardaker, J. B., \& Flaten, O. (2006). Economic sustainability and risk efficiency of organic versus conventional cropping systems. Aspects of Applied Biology, 79, 2006.

Lien, G., Hardaker, J. B., \& Flaten, O. (2007). Risk and economic sustainability of crop farming systems. Agricultural Systems, 94(2), 541-552. http://dx.doi.org/10.1016/j.agsy.2007.01.006

Qiu, L. G. (2001). Development of risk analysis models for decision-making in project management. PhD Thesis submitted to School of the Built Environment, Napier University, Edinburgh, UK.

Savvakis, C. S. (1994). Risk analysis in investment appraisal" Project Appraisal Journal, 9(1), 3-18.

Saunders, J. F., \& Lewis, W. M. (2003). Implications of climatic variability for regulatory low flows in the South Platte River basin. Colorado. J. Am. Water Resource Association, 39, 33-45. http://dx.doi.org/10.1111/j.1752-1688.2003.tb01559.x

Tariq, M., Alzidgali, M. A. H., Rajinder, K. S., \& Kheiry, H. M. I. (1993). South Batinah Integrated Study. Soil survey and land classification project, 3 .

Quiroga, S., Fernandez-Haddad, Z., \& Iglesias, A. (2010). Risk of water scarcity and water policy implications for crop production in the Ebro Basin in Spain. Hydrology and Earth System Sciences Discussions Journal, 7, 5895-5927. http://dx.doi.org/10.5194/hessd-7-5895-2010

\section{Copyrights}

Copyright for this article is retained by the author(s), with first publication rights granted to the journal.

This is an open-access article distributed under the terms and conditions of the Creative Commons Attribution license (http://creativecommons.org/licenses/by/3.0/). 